\title{
Research on Coupling of Financial Innovation and Technology Innovation in Hebei Province
}

\author{
Shuangsheng Shen ${ }^{1,2}$ lina Zhao ${ }^{1,2}$ Jia Wang $^{1,2}$ \\ ${ }^{1}$ Experimental Teaching Center, Hebei Finance University, Baoding, 071051, China \\ ${ }^{2}$ Science and Technology Financial Key Laboratory of Hebei Province, Baoding 071051, China
}

Keywords: Financial innovation, Technological innovation, Coupling model, Coupling model

\begin{abstract}
In order to further explain the essence of financial innovation and technological innovation, this paper constructs the coupling model and the coupling coordination model based on the characteristics of financial innovation and technological innovation, and takes Hebei Province as an example to carry out the empirical analysis. The results of the research, the innovation of science and technology, the coupling system of financial innovation has experienced low level coupling, antagonism and running in three stages, the coupling system is mature, and the contribution of financial innovation in the coupling system is greater than that of scientific and technological innovation.
\end{abstract}

\section{Introduction}

In recent years, some scholars in physics coupling theory is introduced to the field of economics, such as Sheng bin Hao, Yu Bo (2008) and spatial (2011). Wang Yongsheng (2014) believes that the coupling relationship between technological innovation and financial innovation is a double helix structure, and the evaluation model of the coupling coordination degree of financial innovation and scientific and technological innovation is constructed. Zheng Meng (2013) the establishment of a loose coupling model of China's scientific and technological innovation and the role of financial innovation mechanism. Through the above analysis, it can be seen that the combination of scientific and technological and financial research methods, with a view to further tap the combination of scientific and technological innovation and financial innovation system, to provide more scientific and technological innovation and financial innovation to provide a more complete theoretical analysis, more accurate and more effective policy recommendations.

\section{Study on the coupling mechanism system of scientific technological innovation and financial innovation}

Coupling is a measure of two or more than two entities that are mutually dependent on each other. The basic premise of the coupling is that there is a certain correlation between the coupled subsystems. The result is that the properties of the subsystems will change to some extent. As the two subsystems of innovation system and technology finance, the interaction and mutual promotion between scientific and technological innovation and financial innovation can produce the economic effect of synergy, so there is a coupling relationship between scientific and technological innovation system and financial innovation system, and the two main body and multi level coupling behavior constitute the scientific and technological innovation and financial innovation coupling system.

$$
\begin{array}{r}
A_{i j}=\max \left(X_{i 1}, X_{i 2}, X_{i 3}, \ldots \ldots, X_{i j}\right) \\
B_{i j}=\min \left(X_{i 1}, X_{i 2}, X_{i 3}, \ldots \ldots, X_{i j}\right) \\
\quad(j=1,2,3, \ldots . . n)
\end{array}
$$




\section{The establishment of the coupling model of scientific and technological innovation and financial innovation}

The establishment of the function. Measure the degree of mutual influence between technological innovation and financial innovation through various coupling elements, usually with the function method. Let $(\mathrm{i}=1,2, \ldots \mathrm{I}(\mathrm{m})$ is the order parameter of the system, which is the first I of the financial innovation system, and the contribution of $\mathrm{J}$ to the coupling system is the effect of the system. The value is $(\mathrm{i}=1,2), \ldots \mathrm{M})$. The coupling system is stable when the threshold for the index,. The threshold value is:

$$
\begin{gathered}
A_{i j}=\max \left(X_{i 1}, X_{i 2}, X_{i 3}, \ldots \ldots, X_{i j}\right) \\
B_{i j}=\min \left(X_{i 1}, X_{i 2}, X_{i 3}, \ldots \ldots, X_{i j}\right) \\
(\mathrm{j}=1,2,3, \ldots . . \mathrm{n})
\end{gathered}
$$

Science and technology innovation and financial innovation coupling system is a comprehensive evaluation index system, which is divided into positive and negative indicators. Positive index has positive effect on the coupling system. The greater the value of the index value, the more negative effect of the inverse index on the coupling system. The function of scientific and technological innovation system and financial innovation system can be expressed as:

$$
U_{i j}= \begin{cases}\left(X_{i j}-B_{i j}\right) /\left(A_{i j}-B_{i j}\right), & X_{i j} \\ \left(A_{i j}-X_{i j}\right) /\left(A_{i j}-B_{i j}\right), & X_{i j}\end{cases}
$$

In the range $[0,1]$, said the index reached target value of satisfaction, reaching to 1 expressed more satisfaction, closer to 0 is not satisfactory. The contribution of the system of scientific and technological innovation and the financial innovation subsystem can be used to realize the contribution of the coupling system order parameters. The linear weighted average method is adopted in this paper:

$$
U_{i}=\sum_{i=1}^{2} w_{i j} \cdot X_{i j}(j=1,2,3, \cdots \cdots n)
$$

$U_{i}$,is contribution from the subsystem to the total system ,the weight of each index is determined by objective weighting method. First determine the coefficient of variation of the evaluation index, and then calculate the weight of each index according to the coefficient of variation.

$$
\begin{gathered}
v_{i j}=\sigma_{i j} / \overline{X_{i j}} \\
w_{i j}=\sigma_{i j} / \sum_{j=1}^{n} v_{i j} \\
\sum_{j=1}^{n} w_{i j}=1
\end{gathered}
$$

$\sigma_{\bar{i} j}, \overline{X_{i j}}$ are the standard deviation and mean value of the data from the I of the coupling system. The greater the weight, the greater the impact of the index on the overall efficacy of the value. 
Building the coupling function. The coupling degree function of scientific and technological innovation and financial innovation is obtained by using the concept of capacity and coefficient model of Physics:

$$
C=\left\{\left(U_{1} \cdot U_{2}\right) /\left[\left(U_{1}+U_{2}\right)\right]\right\}^{1 / 2}
$$

Among them, $U_{1}, U_{2}$ said that the contribution of scientific and technological innovation system and financial innovation system to the coupled system, that is, the comprehensive order parameters of technological innovation system and financial innovation system.C coupling degree value for the coupled system. For the innovation of science and technology, the coupling degree of the system is described as follows: quantitative description of the dynamic changes of the cooperative development of the coupled system, which reflects the relationship between the number of the interaction between the technology innovation system and the financial innovation system in a certain period of time. Coupling degree [0 range 1], C. According to the evolution of technological innovation and financial innovation system is divided into three stages:

Table 1. Division standard for coupling degree

\begin{tabular}{cll}
\hline $\begin{array}{c}\text { coupling } \\
\text { degree }\end{array}$ & coupling standard & \multicolumn{1}{c}{ coupling interpretation } \\
\hline$\left[\begin{array}{ll}0,0.3\end{array}\right]$ & Low level coupling & $\begin{array}{l}\text { system has the low level of development, and the } \\
\text { subsystems are not related to each other. }\end{array}$ \\
\hline$\left(\begin{array}{lll}0.3,0.7\end{array}\right]$ & Middle level coupling & $\begin{array}{l}\text { subsystem has a high level of development and interaction is } \\
\text { obvious, there is a certain degree of coupling }\end{array}$ \\
\hline$\left(\begin{array}{ll}0.7,1.0\end{array}\right]$ & High level coupling & $\begin{array}{l}\text { subsystems are highly developed, and the interaction } \\
\text { between each other to achieve the maximum level, the sub } \\
\text { system of harmonious interaction, common into the high } \\
\text { level of coupling }\end{array}$ \\
\hline
\end{tabular}

Coupling coordination function. Coupling degree is an important index to reflect the degree of coupling between scientific and technological innovation and financial innovation. It is very important to distinguish the degree of coupling effect of scientific and technological innovation and financial innovation and the development of the two. But coupling model of its own limitations, such as the threshold function inconsistencies weights determine the unity of law, to rely solely on the coupling to determine the degree of coupling state scientific and technological innovation and financial innovation will be misleading. Therefore, the coupling degree function is further improved to construct the coupling coordination degree model of technological innovation and financial innovation:

$$
\left\{\begin{array}{l}
H=(\mathrm{C} * \mathrm{~F})^{1 / 2} \\
F=\alpha U_{1}+\beta U_{2}
\end{array}\right.
$$

$\mathrm{H}$ is a coupling degree, $\mathrm{C}$ is the coupling degree, $\mathrm{F}$ is the comprehensive coordination index of scientific and technological innovation and financial innovation, and the $+=1$ is determined by objective weight. The coupling degree can be roughly divided into several stages by combining the relevant rules and related documents:

Table 2. Standard table for coupling coordination degree

\begin{tabular}{ccc}
\hline Coupled coordination $\mathrm{H}$ & Coupling Degree & Coupling interpretation \\
\hline 0 & no coupling & not coordinated basic \\
\hline$(0,0.3]$ & low level coupling & not coordinated basic \\
\hline$(0.3,0.5]$ & antagonistic phase & barely coordinated \\
\hline$(0.5,0.8]$ & running in period & more coordinated \\
\hline$(0.8,1)$ & high level coupling & High coordination \\
\hline 1 & complete coupling & complete coordination \\
\hline
\end{tabular}


Coupling index system. The development of science and technology innovation system can be measured from three aspects, including scientific and technological innovation resources, scientific and technological innovation ability and technological innovation environment. The measure of financial innovation subsystem can be measured from the efficiency of financial innovation, financial innovation and financial innovation structure. In order to meet the scientific and systematic evaluation, and consider the availability of data, the establishment of scientific and technological innovation and financial innovation and coupled system evaluation index system is as follows:

Table 3. Index system and weight of coupling degree of scientific and technological innovation and financial innovation

\begin{tabular}{|c|c|c|c|}
\hline $\begin{array}{c}\text { Order } \\
\text { parameter }\end{array}$ & First index & Second index & $\begin{array}{l}\text { weight of } \\
\text { index }\end{array}$ \\
\hline \multirow{5}{*}{$\begin{array}{l}\text { Science and } \\
\text { technology } \\
\text { innovation }\end{array}$} & \multirow{2}{*}{$\begin{array}{l}\text { technology } \\
\text { innovation resources }\end{array}$} & $\begin{array}{c}\text { R\&D spending accounted for the proportion of main } \\
\text { business }\end{array}$ & 0.0778 \\
\hline & & R\&D total people X13 & 0.1216 \\
\hline & \multirow{2}{*}{$\begin{array}{l}\text { technology } \\
\text { innovation ability }\end{array}$} & $\begin{array}{c}\text { Total number of scientific and technological innovation } \\
\text { capacity (unit: item) X13 0.2398 }\end{array}$ & 0.2398 \\
\hline & & Technical market turnover (unit: million) X14 0.2191 & 0.2191 \\
\hline & $\begin{array}{c}\text { technology } \\
\text { innovation } \\
\text { environment }\end{array}$ & $\begin{array}{l}\text { financial science and technology grant (unit: million yuan) } \\
\qquad \text { X15 0.3417 }\end{array}$ & 0.3417 \\
\hline \multirow{4}{*}{$\begin{array}{l}\text { Financial } \\
\text { innovation }\end{array}$} & $\begin{array}{l}\text { efficiency of } \\
\text { financial innovation }\end{array}$ & $\begin{array}{l}\text { financial institutions loan balance (unit: million) X21 } \\
\qquad 0.2685\end{array}$ & 0.2685 \\
\hline & \multirow{2}{*}{$\begin{array}{l}\text { Stage of financial } \\
\text { innovation }\end{array}$} & $\begin{array}{l}\text { inancial industry practitioners (units: million)) X22 } \\
0.1197 \\
\end{array}$ & 0.1197 \\
\hline & & $\begin{array}{l}\text { Fixed asset investment in financial industry (unit: million) } \\
\text { X23 } 0.3349\end{array}$ & 0.3349 \\
\hline & $\begin{array}{l}\text { Structure of financial } \\
\text { innovation }\end{array}$ & $\begin{array}{l}\text { Insurance premium income (unit: million) of financial } \\
\text { innovation structure insurance institution X24 } 0.2768\end{array}$ & 0.2768 \\
\hline
\end{tabular}

\section{Scientific and technological innovation and financial innovation coupling empirical research}

In this paper, Hebei province science and technology innovation system and financial innovation system as the two sub system, Hebei province science and technology innovation and financial innovation and financial innovation of the research object, through the method of quantitative measurement, to explore the relationship between science and technology innovation and financial innovation in Hebei Province, in order to provide theoretical basis and practical guidance for the development of science and technology innovation and financial innovation in Hebei province.

Data processing and calculation. This study selects the economic data of scientific and technological innovation and financial innovation in Hebei Province in province for empirical analysis. According to the coupling model of scientific and technological innovation and financial innovation, the order parameters of the science and technology innovation subsystem and the financial innovation subsystem are calculated respectively, and the weight of each index is shown in Table 3, which is shown in Table 4. 
Table 4. Empirical results of coupling degree and coupling degree of scientific and technological innovation and financial innovation

\begin{tabular}{ccccc}
\hline Year & $\begin{array}{c}\text { the science and } \\
\text { technology } \\
\text { innovation order } \\
\text { parameter U1 }\end{array}$ & $\begin{array}{c}\text { financial } \\
\text { innovation order } \\
\text { parameter U2 }\end{array}$ & coupling degree C & coupling degree H \\
\hline 2003 & 0.0216 & 0.0098 & 0.0067 & 0.0104 \\
\hline 2004 & 0.0177 & 0.1620 & 0.0160 & 0.0365 \\
\hline 2005 & 0.0663 & 0.1466 & 0.0457 & 0.0685 \\
\hline 2006 & 0.1555 & 0.2657 & 0.0981 & 0.1420 \\
\hline 2007 & 0.2958 & 0.2758 & 0.1427 & 0.2023 \\
\hline 2008 & 0.3375 & 0.4487 & 0.1926 & 0.2734 \\
\hline 2009 & 0.4529 & 0.5600 & 0.2504 & 0.3544 \\
\hline 2010 & 0.5701 & 0.6796 & 0.3100 & 0.4384 \\
\hline 2011 & 0.7123 & 0.8713 & 0.3919 & 0.5545 \\
\hline 2012 & 1.0000 & 1.0000 & 0.5000 & 0.7071 \\
\hline
\end{tabular}

Coupling results of scientific and technological innovation and financial innovation. Table 4 shows that the effect of the interaction between science and technology innovation subsystem and financial innovation subsystem is increasing, which shows that the contribution of scientific and technological innovation and financial innovation in Hebei province is weak to significant. Considering the coupling degree and coupling degree of scientific and technological innovation and financial innovation, the coupling system of scientific and technological innovation - financial innovation has experienced low level coupling, antagonism and running in three stages, the coupling state of scientific and technological innovation - financial innovation is close to the trend of the rise of a straight line, the specific performance is as follows:

a). One of the slave subsystems on the coupling efficiency value, innovation of science and technology and the innovation of the financial contribution of the coupled system presents rising trend, illustrated with Hebei Province scientific and technological progress and financial development, both of the coupled system with more and more, but most of the contribution of the year financial innovation subsystem of the coupled system to more than the contribution of science and technology innovation system of the coupled system, indicating that Hebei Province on the financial innovation of science and technology innovation support, but science and technology innovation efficiency is low, the support of financial innovation is poor.

b). The measurement results of the coupling degree and the coupling degree show the difference. The results show that the limit value of the order parameters of the two sub systems of scientific and technological innovation and financial innovation have a greater impact, so the research on the coupling of scientific and technological innovation and financial innovation in Hebei province. The coupling degree of scientific and technological innovation and financial innovation in Hebei province is very low, and the contribution of the two is very small, the development level of science and technology innovation system and financial innovation system is relatively low, and the interaction is not obvious. The coupling degree of science and technology innovation and financial innovation is still at a low level, but the speed of the rise is great, which shows that the system and the interaction between the elements of the system and the subsystems of the financial innovation system in the five years of the rapid development of the system and the interaction between the system and the 2006-2010 system are in the stage of reluctance. 2011-2012 years of scientific and technological innovation - coupled with the development of financial innovation system to the running period, the system is more coordinated, the coupling mechanism is gradually mature, and the system has begun to develop a cooperative development between the system.

c). Overall, Hebei province science and technology innovation system and financial innovation system in ten years has been rapid development, but the basis of scientific and technological innovation and financial innovation is weak, so that the development of financial innovation and financial innovation system has been limited. The investment scale and the intensity of the investment in scientific research R\&D are the main means to realize the independent innovation, but the investment is not considerable. On the other hand, the development of the science and technology 
departments and the financial sector tends to develop in a single side, and the organic combination mechanism and the interaction are not satisfactory. The government pays much attention to the development of the financial system to support scientific and technological innovation, but the financial system, which is dominated by banks, still makes the results of scientific and technological innovation and commercial bank's credit principle.

\section{Conclusions and policy recommendations}

Science and technology and finance are the two engines of economic and social development. The development of scientific and technological innovation and financial innovation is the key to the development of science and technology in Hebei Province, but there is still a lot of room for innovation in Hebei province. Hebei province should further strengthen the combination of scientific and technological innovation and financial innovation, realize the economic development, we must adjust their behavior in order to adapt to the development of science and technology innovation and financial innovation coupling system, so that the two are in the direction of the coupling coordination and mutual benefit.

First of all, the establishment of scientific and technological innovation - financial innovation and collaborative development of information service platform. Science and technology innovation and finance innovation system information to each other is not complete, leading to the two subsystems in a certain extent, showing the "fragmentation". Therefore, efficient, comprehensive, transparent technology innovation - financial innovation information service platform is two collaborative development focus of the work; second, improve the system of financial innovation support long-term mechanism of scientific and technological innovation. The development of science and technology enterprises will experience some stages, such as start-up, development, maturity and so on. At the same stage, there are big differences in the size of enterprises, the ability to resist market risk, technological innovation ability, and so on. To a certain extent, financial innovation is the interpretation of scientific and technological innovation in the financial field. The development of financial innovation depends on the development of related technology.

\section{Acknowledgments}

This article is the open fund project of Key Laboratory of science and technology and finance of Hebei Province, No.: HBTFKL201418.

\section{References}

[1] Wu Yuling, Bai Ling. Coupling coordination and interaction analysis between urbanization and environmental system in Guangxi. Geography Science, 2011,31 (12): 1474-1479.

[2] Guo Hongwei, Guo Xiuying, Yang Xiaolei. scientific and technological innovation and financial innovation model to explore the development of Heilongjiang Province,. Financial line of sight, 2014,3:85,87.

[3] Zhu Guiju, Zhang Jianming, $\mathrm{Hu}$ Xiaoyuan. Research on the current situation and Countermeasures of Hunan province science and technology finance research. Enterprise technology development, 2010,29 (13): 114-115124.

[4] Wang Yongsheng, Ao Haiyan, Chen Hang. Financial innovation and technological innovation coupling coordination scheduling evaluation research. Journal of Shenyang University of Technology (SOCIAL SCIENCE EDITION), 2010,7 (1): 1-12. (18): 1-5.

[5] Zheng Meng, Hu Guohui. The mechanism and mode of the coupling of scientific and technological innovation and financial innovation to explore the financial innovation of. Financial innovation, 2014,10:20-23. 
[6] Duan Shide, Xu Xuan. Research on the development of strategic emerging industries of science and technology and financial support. Technology progress and countermeasures, 2011,28 (14): 66-69.

[7] Ma Hong Research on the combination of science and technology and financial Southwestern University of Finance and Economics, Sichuan: Southwestern University of Finance and Economics, 2013:1-187.

[8] Lu Jingui, Chen Zhenquan. Research on the problem of combination of technology and Finance: from the perspective of Guangdong. Southern finance, 2009,6:68-70.

[9] Hao, Shengbin Yu Bo. Coupling degree model of enterprise technology management capability and technology capability and its application. Forecast, 2008, 6:12-15. (27). 